\title{
Beyond Objectivism and Relativism: Kuhn's Deconstruction of the Scientific Method as a Road Map to Social Epistemology
}

\section{Kole Jimoh A*}

Department of Philosophy, Catholic Major Seminary of all saints Peter and Paul, Nigeria

*Corresponding author: Anselm Kole Jimoh, Department of Philosophy, Catholic Major Seminary of all saints Peter and Paul, Bodija, Ibadan, Nigeria, Email: jimohanselm1@yahoo.com

\section{Research Article}

Volume 3 Issue 3

Received Date: August 18, 2020

Published Date: September 23, 2020

DOI: $10.23880 /$ phij-16000153

\section{Abstract}

The idea that truth, knowledge and rational thoughts is fundamental to the theory of knowledge. In his work "structure of scientific revolution", Kuhn disagrees with this idea in his detailed analysis of how scientific paradigms are developed. Scientist accept the dominant paradigm until anomalies are thrown up. Scientist then begin to question the basis of the paradigm itself; new theories emerge which challenge the dominant paradigm and eventually one of the new theories become accepted as the new paradigm. (Anselm 1) The significantly shifted focus to the socio-cultural dimensions of knowledge, which current discussions within social and collective epistemology is exploring to enrich our process of knowledge practice. This paper attempts to presents Kuhn's idea of paradigm shift as a welcome attitude to knowledge inquiry as new paradigm better explains the observations, pave way for other models of knowledge acquisition also and offers a model that is closer to the objective, external reality.

Keyword: Knowledge; Science; Epistemology; Objectivism

\section{Introduction}

This work explores the notion of science as a paradigm for rational enquiry and evaluates it in the light of Kuhn's deconstruction of the scientific method. It assesses the plausibility of conceiving knowledge, truth, and rational certainty from the perspective of the perceiver and argues that the idea of relating knowledge, truth, and rational certainty from the perspective of the cognitive agent and argues that the idea of objectivity as universal standards and paradigms, be replaced with the idea of relating knowledge, truth, and rational certainty to the context within which epistemic claims are produced. This attitude to knowledge is what social epistemology advocates. Such an attitude facilitates tolerance and acceptability in rational enquiry and therefore, leads to growth in knowledge practice by providing a richer understanding of reality as against the rigid restrictions of the notion of objectivity, which stifle the growth of knowledge. (Anselm, 116)

Anselm further highlight that every epistemic claim affirms a particular process of knowing. This process takes place within a particular context that has implications for the claim it produces. Therefore, no claim to knowledge is independent of the processes that produce it. Hence, we talk about procedural methods as authenticating and providing justifications for epistemic claims. The exploit of science, coupled with the consequent claim by positivists that science is the paradigm for knowledge, necessitates the need to define the scientific method and establish the veracity of the paradigmatic role of science. The practice of traditional epistemology assumed that science aims for the truth. The truth here is conceived as that which mirrors reality in its indifferent and unchanging state. These developments culminated in the positivists' claim that scientific method of inquiry provides infallible foundations for knowledge and 


\section{Philosophy International Journal}

therefore, seeks to enthrone science as the paradigm for knowledge.

"In the Structure of Scientific Revolutions, Kuhn developed a novel and interesting account of the dynamics of scientific change, one that was deeply at odds with the assumptions that had previously informed the outlook of philosophers of science" (Anselm, 116). According to him, scientific knowledge is not cumulative as we traditionally assume and observational data do not provide a foundation for scientific knowledge. He argues that scientists cannot be univocal in settling disputes by appealing to data because the data they work with are pliable. In his opinion, scientists not especially open-minded or critical, they are more dogmatic with respect for theories. For him, scientific theory is tradition-bound (116). The implication of Kuhn projects is that there are many systems of justification and each with his own standard of justification. By implication, rational choice between the various systems of justification is implausible. With his notion of incommensurabilty Kuhn developed this argument and provides the room for the interpretation that knowledge, truth, and rational certainty are meaningful only when contextualized. This makes his epistemology evolutionary and social.

\section{Challenges of Kuhn's paradigm vis-à-vis Traditional epistemology}

According to Anselm Jimoh, issues about how we establish the nature of knowledge narrows down to issues about justification and traditional modern epistemologists consider justification, either as correspondence or a matter of coherence. However, the do not agree on the number of alternative system on which coherence is established. The positive exploits of science in the age of enlightenment and renaissance projected science as a reliable system of enquiry. Consequently, many philosophers regard science as superior of other systems of inquiry (Anselm 175). Orman W.V Quine, Karl Popper and Wilfred Sellars, among others, admit that science provides the most reliable system of explanation. For the logical positivist, science is the paradigm for knowledge because it provides a greater certainty based on its method of rigorous collection of data, observations, experimentation, and generalization. The methods of science, for them, secures precision and reliability (Jimoh, 117). Therefore, genuine knowledge falls within the realms of science, which includes, the formal sciences of logic and mathematics and the empirical sciences.

Science became a popular catchwood to describe knowledge par excellence such that we are constrained to think that unless we arrive at our epistemic claims through the procedural methods of science, they are not justified. The scientific method, regarded as the most reliable in the search for rational certainty and justification of epistemic claims is "the way techniques are selected in science; that is, the evaluation of alternative courses of scientific action (Ackoff cited in Jimoh 117). It refers to the rules that guide scientists in decision making and choices; the general procedures that guide the conduct of scientific research.

Imre Lakatos who introduces the concept of "research programme" supports the idea that science is the paradigm of genuine knowledge because it is a deliberate research programme, in the sense that it is an undertaking for the purpose of discovery, which has heuristic value. By research programme, Lakatos refers to the professional network of scientists who are inquiring into how best to improve scientific theories in order to facilitate a better understanding of nature and how nature works. He used the notion of research programme to blend and revise popper's theory of falsification, which presents a normative model of science and Kuhn's idea of normal science, which is a descriptive model of science. Popper's theory of falsification is a criterion for demarcation that draws a sharp line between what is scientific and what is non-scientific, therefore, scientific theories exclude theories that contain statements that are not falsifiable. This is popper's alternative to verificationism, which is the theory that a statement must be true in principle and empirically verifiable before it can be counted as meaningful and scientific. As it were, Lakatos and Popper agree on science as a paradigm for knowledge but they disagree on the criteria for establishing what is scientific and what is non-scientific.

Notwithstanding, the wide spread tendency to regard science as paradigmatic for knowledge, many Philosopher's acknowledge that science is one among other alternative systems for problem solving and explanations. Those who argue in favour of science as paradigmatic for knowledge claim that it holds a place of prominence among explanatory and problem-solving systems. Others maintain the modest position that there is no possibility of deciding between equally coherent alternatives within science. This latter call for an interrogation of the procedural methods of science, which in turn reveals that there is no clear-cut procedural stage in science. For instance, Rusell Achoff talks about three procedural stages in science: Observation, experimentation and generalization. A. D'Abro talks about four stages: observation, experimentation, theory, and mathematics(D'Abro cited in Jimoh 117). F.H Giddings talks about six stages: formulating the problem, constructing the model, testing and controlling the solution from the model, testing and controlling the solution, and implementing solution. There is an apparent lack of agreement among scholars regarding the proper procedural stages in science. This raises the question whether a method that lack clearcut procedural stages should hold a place of prominence 


\section{Philosophy International Journal}

over and above other methods of enquiry. Kuhn's response to this question constitutes his deconstruction of science as a paradigm for knowledge, truth, and rational certainty.

\section{Kuhn's Deconstruction of Science}

Scientific objectivity is the view that scientific theories, laws and experimental results and observations constitute accurate representations of the external world. Kuhn rejects this view and argues that there is no such thing as. According to him neither logic nor observation, or any rational consideration, play a role in the account of theory formation. In other words, it is a system of arbitrary activities. He insists that judgment made within science cannot claim that authority of established truth and that the education of scientists is dogmatic as it does not invite the students to question the accepted theory (Kuhn 361-62). For him, "the history of science displays a secession of 'paradigm' sets of assumptions and examplars which condition the way scientists solve problems and understand data and which are only overthrown in occasional 'scientific revolution' when scientists switch from one theoretical faith to another (Papineau cited in Jimoh 118).

Scientific paradigm is universally recognized scientific achievements that for a time provide model problems and solutions to a community of researchers (Kuhn 10). This stipulative definition suggests a periodical or contextualized understanding of scientific theory. It implies that a given work is to be understood within the period it is relevant and applicable. The scientific paradigm, which is very fundamental to Kuhn's notion of "normal science", consists of two components:

i. A set of fundamental theoretical assumptions that all the members of a scientific community accepts at a given time.

ii. A set of examplars or particular scientific problems that have been solved by means of those theoretical assumptions, and that appears in the textbooks of the discipline in question.

A scientific paradigm is therefore, "an entire scientific outlook that consists in the beliefs, assumptions and values uniting the whole scientific community and allowing normal science to take place (Jimoh 179). The contents of a scientific paradigm include:

What is to be observed and scrutinized, the kind of questions that are to be asked and probed for answers in relation to the subject in question, how the questions are to be structured, how the results of scientist investigations should be interpreted, and how an experiment is to be conducted and what equipment is available to conduct the experiment(179).
Normal science refers to the use of scientific paradigm by scientists to solve problems that arise in the scientific community. There comes a time however, when a scientific paradigm, no matter how successful it has been in problemsolving, becomes incapable of resolving problems. In other words, scientific paradigms encounter problems which they are incapable of accommodating at some point or times. At such times, new paradigms are developed to accommodate the problems. This is the point of scientific revolution when a theory-choice between the new paradigm and the former paradigm takes place.

A scientific revolution is a "period of great upheaval when existing scientific ideas are replaced with radically new ones" (Okasha cited in Jimoh 118). Although it is not an everyday affair, it is however, a relatively frequent phenomenon in the scientific community when a completely new set of ideas overthrows the hitherto existing set if ideas. Scientific revolutions are occasioned by theory-choice. Theory-choice occurs when the members of scientific community makes a choice between two paradigms. According to Kuhn, the members of a scientific community do not have objective criteria or agreeable decision-making procedure, which may lead the individuals in a group to the same decision. (Kuhn, 200) Therefore, allegiance to a new dispensation, which he refers to "paradigm shift", does not necessarily depend on any empirically convincing body of evidence. The reason for the choice is a particular scientific theory is invariably personal and subjective. Kuhn uses the term "incommensurability" to explain this position.

By incommensurability, Kuhn means that there is no common grounds for comparism between the theory chosen and its rival or alternative theories in a theory-choice. This implies that, it is not possible to understand one paradigm through the conceptual framework and terminology of another or rival paradigm because rival theories cannot be compared directly. In which case, we cannot make a rational choice as to which theory is better than the other. The idea here is that, two paradigms cannot be translated into a common language and therefore, their proponents cannot come in contact each other's point of view. 'Kuhn's analysis is built on the assumption that scientist always view research problem through lens of a paradigm, defined by set of relevant problems, axioms, methodological presupposition, technique and so forth (Jimoh 122). We can immediately infer from this that Kuhn's incommensurable theory is relativistic, but Kuhn would deny this. Freeman Dyson quotes him as saying "I am not a Kuhnian! (Dyson 144) by this, Kuhn rejects the relativism that some thinkers associate with his position and have developed on the basic of his work.

Kuhn's development of the incommensurability thesis is based on his belief that scientific concepts derive their 


\section{Philosophy International Journal}

meaning from the theory within which they play a role. His analysis stresses the Hanson's notion that observation is theory-laden. It means that observations depend on theoretical assumptions that constitute the lens through which they perceived and ultimately conceptualized. By implication, a Newtonian concept for instance, cannot be explained independently of the Newtonian theory in which it is embedded. This is sometime refers to as wholism, which is the fundamental unity oneness that underlies phenomenon. It is the ideal that different parts are all interconnected in such a way that they cannot be understood outside the understanding of the entire whole. Within the context of incommensurability, Kuhn argues that paradigm shift is likened to a conversion experience that is not informed by objective reasons. If a new paradigm gains acceptance in the scientific community it is because of peer pressure of scientists upon one another. A paradigm that has forceful advocate wins widespread acceptance. This led Kuhn to the conclusion that it is false to argue that science embodies rational certainty.as such as advocates that we jettison the notion that science is a paradigm for knowledge and relational certainty.

Kuhn's deconstruction of science questions the rationale behind the idea of objective truth as the so-called scientific method on which this idea is built is itself defective. His analysis of structure of scientific revolution dismantles the notion that there are fixed sets of fact about world that are independent of any particular paradigm. (Jimoh 191). Beliefs about the world are based on paradigm-dependent, which can change when the paradigms change. Kuhn denies inviting to relativism, which mean that arguing for paradigmdependent truth and knowledge does not necessarily mean that truth and knowledge are relative concepts. If knowledge is dependent on paradigm or contexts, it means knowledge is not "objective". The team here means having universal standards that holds same and true for all people at all time in all places, irrespective of contexts and paradigms. If knowledge is not relative and yet it is dependent on contexts. It follows then that knowledge is a relation to context. The emphasis here is on the distinction between "relative" and "relational". while the latter refers to the way two or more concepts are connected and the effects and relevance they have and bear to one another, the latter refers to the dependency of one concept upon the other or the meaning of a concept being dependent on a given state of affair.

\section{Kuhn's Incommensurability: Evolution and Problems}

This section attempts to discuss the evolution and problem of Kuhn's theory of incommensurability. The problem arises in the course of the Kuhnian theory of world constitution. It can be called 'the problem of the position of the analyst', and it has important parallels to similar problems that have repeatedly surfaced in the history of philosophy. A theory of world constitution is called for, I have argued, if one wants to make sense of the thesis that the world changes in a scientific revolution, and if one attempts to produce arguments for that thesis. But what has brought Kuhn to this strange talk about world changes in revolutions? His motive is his experience as a historian of science, from which most of his philosophical intuitions derive. If one scrutinizes the scientific practices of the past, one finds that in many cases these practices make much more sense if one assumes these scientists did indeed work in a world substantially different from ours. Yet this other world is not totally different from ours and therefore not totally foreign to us, but at some characteristic points it differs from ours. For example, there was phlogiston in the world of chemistry before the chemical revolution, the Ptolemaic planets revolved around the the earth, and so on. But in which sense 'was there' phlogiston in the world of pre-revolutionary chemistry? Well, it was there in the same sense as there are electrons in the world of today's physics, or there is evolution in the world of today's biology. That means, roughly speaking, that there are theories that describe and explain these entities and processes, that to different degrees - these entities and processes are subject to experimentation, that they play an essential role in the explanation of diverse phenomena, and so forth. But such a role in a given science, even if played extremely successfully, does not guarantee that later generations of scientists will believe in the same entities and processes, and this holds for past science as well as for present science.

The obvious consequence is this: if one sets out to discover the scientific past in as undistorted a way as possible, then one is well advised not only to 'bracket' one's own idea of reality (Husserl) but to question it, and to open oneself up for different ideas of reality. Otherwise, there is the danger of projecting one's own idea of reality into the past, thereby blocking access to possibly different ideas of reality. The situation is analogous to ethnocentric anthropology or to presentist historiography, which miss the essentially foreign. In particular, the abandonment of one's own idea of reality seems to be an indispensable methodological postulate for even entertaining a general theory of world constitution. The reason is that the theory of world constitution aims to understand the constitution of worlds in general and impartially, that is, unbiased by any particular idea of reality. Therefore, no elements whatsoever may enter this theory that originate from the specific world of the analyst: they would destroy the theory's intended generality and impartiality that must prevail with respect to various ideas about reality. But this postulate apparently cannot be fulfilled. At least in the Kuhnian theory of world constitution, a host of assumptions are used that can be justified only with recourse to the specific world of the 


\section{Philosophy International Journal}

analyst. Many of these assumptions are of an anthropological nature, namely, assumptions concerning cognitive abilities of human beings. Paul Hoyiwvgen lent credence to this when he affirmed that:

"assumptions are made with respect to the abilities to perceive, to understand ostensions, to form concepts, to communicate, and many more. But to gain knowledge about the subjects of world constitution means to treat them as objects belonging to one's own world, and this implies the use of substantial parts of one's own idea of reality" (Paul 481).

As a result, the attempt to construct a general theory of world constitution leads to the uncomfortable situation that the means needed to reach that goal also render its attainment impossible.

The attempt to analyze the constitution of reality in a general and unbiased way, independently of one's own idea of reality, seems predestined to fail because one has to use one's own idea of reality-otherwise one never gets started. Once one gets started, one must necessarily fail. I must admit that I don't know what to do in this methodological situation. We may have learned with difficulty how to live with that fact that the one true religion or the one true culture - one's own, of course - does not exist. It may be - I am not saying that it is the case - it may be that also the idea of the one reality - the one we are used to, of course - must be abandoned. But the learning process required here will not be an easy one.

\section{Objectivism, Relativism and the Evolution of Knowledge}

Objectivism: This term is often used to describe a conceptindependent state of being. That is, "conceiving-independent things, things whose existence do not depend on one's conceiving of them". (Moser cited in Jimoh, 121) It refer to "anything that exists as it is independent of any conscious awareness of it(www.iep.utm.edu/objectiv/Hi). It is the state or quality of being true outside a cognitive agent's individual biases, interpretations, feelings and imaginations. In relation to truth, a proposition is objective when truth conditions of the proposition are net independent of the subjective mind. TE conceive objectivity as a value, which underlies how we attach importance to claims. It associates objectivity with ideas like reality, truth, and reliability. The more objective we assume a claim to be, the more importance we attach to the claim.

Objectivity is a central concept in scientific inquiry that is understood in two fundamentally different ways: (i) As product objectivity and (ii) As process objectivity. As product objectivity, it means the products of science, for example: theories, laws, experimental results and observation, are accurate results of the external world. This implies that the product or results of science are not subjected to, or influenced by human factors like: desires, goals, capabilities or experience. (Reiss \& Sprenger, encyclopedia of Philosophy). As process objectivity, it means "the processes and methods that characterize (science) neither depend on contingent social and ethical values, nor on the individual bias of a scientist.

As a term, objectivity goes with some rhetorical force, which gives science an admirable place and authority in public parlance. It is conceived as faithfulness to facts; a faithful description of facts out there in the world. This is based on the assumption that there are facts out there in the world, which science must discover, analyse, and systematize. Therefore, a claim is objective if it is successfully or faithfully describes or applies to the fact out there in the world. In addition to this, objectivity is also conceived as value-free or absence of normative commitments and freedom from personal biases, which is a form of inter-subjectivity.

Following the assumption that it is objective, the scientific method is considered superior to other systems of inquiry. If this is truly the case, then it is worth defending. But over the years, philosophers of science closely examined scientific practice and conclude that, "the several conceptions of the ideal of objectivity are either questionable or unattainable" (Jimoh 125). Post traditional modern philosophy reasons in line with "philosophy after objectivity", which Paul Moser conceptualizes thus:

Philosophy after realism and idealism, assuming agnosticresistant non-question begging evidence for neither realism nor idealism. Such philosophy endorses making senseexplaining in perspective, without presumptions of nonquestion begging evidence for claims to objectivity...[It] shifts focus to semantic and purpose-relative instrumental constraints for explanations, evaluations, and justifications. As a result, the decisive roles of inquirers in inquiry, including philosophical inquiry, take centre stage (Moser 17 cited in Jimoh).

Some of the commentaries on Kuhn claim that his work is ontologically positivist, which implies objectivism, because his epistemological postulations suggests a better understanding of objective reality occasioned by the new paradigm. Kuhn disagrees with these understanding of his work and he insists that we should jettison the idea that paradigm shift brings the scientist closer to the truth. According to him, we are traditionally accustomed to thinking that science constantly leads us closer to some goal that nature has set in advance. There is no need for such goal as we can account for the existence of science, as well as its success in term of evolution form the state of knowledge in the community at any given time (Kuhn 170-171). 


\section{Philosophy International Journal}

Relativism: The argument against epistemic objectivism are often termed relativist. From a universally applicable, objective standpoint (Jimoh 126). This is the view that there are no absolute truths or validity, that claims have subjective or relative value according to the differences in their perceptions and considerations. Critiques of relativism conceive it as "the thesis that all points of views are equally valid" (126).

Relativism is not a single doctrine. It is a family of views with the common theme that certain central aspect of experience, thought, evaluation and/or reality to something else, like justification standards. For instance, truth is something said to be relative to language, culture, or biological makeup (Jimoh 126). This makes the definition and the ground for establishing epistemic relativism difficult and unclear. According to Maria Baghramian and Adam Carter, "despite a long history of debate going back to Plato and an increasingly large body of writing, it is still difficult to come to an agreed definition of what, at its core, relativism is, and what philosophical import it has" (126). The general idea is that any argument in favour of relativism is an argument against absolutism. This implies that, "at least some class of things have the properties they have not simpliciter, but only relative to a given framework of assessment and correspondingly, that the truth of claims attributing these properties holds only once the relevant framework of assessment is specified or supplied (127).

Defenders of relativism conceive it as a harbinger of tolerance and the only epistemic position that open-minded and tolerant thinkers can embrace. Critiques of the idea of relativism dismiss it as incoherent and uncritically permissive intellectually. Contemporary philosophers however, seem to be more embracive of the idea of epistemic relativism as the thesis that the cognitive norms which account for knowledge and the rational justification of beliefs vary with local conceptual and cultural frameworks.

The positive attitude of contemporary philosopher's to epistemic relativism has its grounding on three key assumptions:

i. That epistemic justification is framework relative.

ii. That there are many genuinely alternative, even incompatible, epistemic systems.

iii. That we cannot demonstrate in a non-circular way that our epistemic system is superior to any other (Williams 94).

Based on these assumptions, relativists claim that, either we maintain the chauvinistic position that our epistemic system is superior to all other alternatives or we accept that alternative systems are equally legitimate.
Just like some scholars some scholars interpret Kuhn's work to be objectivistic, some have also interpreted his work to be relativistic because, for them, has analysis of "paradigm shift" suggests that the truth of a claim is relative to the paradigm employed in establishing the claim. This interpretation is mistaken because it presupposes that Kuhn's notion of incommensurability means incomparability. On the contrary, incommensurability does not mean theories cannot be compared but that theories cannot be compared in terms of a system of common measure. (Sharrock \&Rupert 2002) Kuhn's analysis shows that every paradigm presupposes a prior paradigm and build upon itself leading to a fundamental increment in a structure of development that could be described as referential and not necessarily relative. Kuhn himself denies that he is a relativist. He argues that development in science is a unidirectional and irreversible process in which more current scientific theories provide better puzzle-solving tools than earlier scientific theories. According to him, this is not a relativist's position.

The Evolution of Knowledge: The notion of epistemic objectivity in the sense I have employed it in this paper relegates to the background the fundamental role of the doxastic agent in knowledge-practice and the social dimensions of knowledge. This is a characteristic feature of TE, which current discussions in social and collective epistemology seek to rectify. It significant to identify and accurately determine the roles of the doxastic agent in knowledge-practice, as well as the social factors that influence cognition. Such an endeavor will open up the domain of knowledge. Consequently, our understanding of reality would progressively evolve and provide a more genuine and accurate knowledge of what is the case and what is not the case.

Kuhn's critique of the scientific method is a key contribution to the philosophy of science, which has directed attention to the epistemic relevance of the social dimensions of scientific enquiry. His Structure of Scientific Revolution reveals that scientific inquiry is a complex social activity and to limit ourselves to the logic of science would limit what we can learn about science and scientific knowledge. Although Kuhn did not describe his project as a social epistemology (SE), which as a concept only became popular among philosophers in the 1980's, his epistemology of science is definitely SE(Wray cited in Jimoh).

SE means different things to different scholars. For the likes of Federick Schmitt, it means the study of expertise or testimony as sources of knowledge (Schmitt 1-27). For Steve Fuller, it refers to policy issues in science, for instance, should, and to what extent should the public, which pays for science through taxation, shape the agenda for research 


\section{Philosophy International Journal}

program in science. (Goldman\&Blanchard 2015) For Warren Schmaus, SE concerns the role of the social charactersitc of the inquirers in developing an objective account of the world Schmaus 127-137). SE is a shift from the emphasis of TE on individual doxastic attitudes in abstraction from their social environment. It places emphasis on the epistemic effect of social interaction and systems. This is a bid to rectify the imbalance of TE that seems not to take into consideration the human epistemic situation., shaped largely by social relationships and institutions(Goldman\& Blanchard 2015).

It is an expanding field of inquiry, which investigates certain aspects of knowledge paractise. These aspects include: testimony, peer disagreement, epistemic relativism, epistemic approaches to democracy, evidence in the law, the epistemology of mass collaboration and judgement aggregation. (Goldman, 11) Alvin Goldman identifies three varieties of SE: (i) The individual doxastic Agents (IDAS) with social evidence, (ii) The collective doxastic agents (CDAS), and (iii) system-oriented (SYSOR) social epistemology(14).

Within the context of the above notion of SE, I consider Kuhn's project as a clarification of the role of the social dimensions in scientific inquiry and how these social dimensions contribute to the success of science. According to Kuhn, the socialization process of scientists makes them as effective as they are. The summary of his argument is that: (i) scientific knowledge is produces by groups. (ii) scientific change is a social change. And (iii) Philosophers of science must draw on social scientific research to develop an adequate epistemology(172).

\section{Conclusion}

The focus of TE has been on individual doxastic agents and their doxastic states. The focus tries to formulate the criteria by which we evaluate the individual doxastic agent's cognitive states in knowledge practice. It overlooks the epistemic influences of social interactions and systems, thereby limiting the scope of epistemic inquiry. Kuhn's project on scientific inquiry, which essentially deconstructs the myth of the scientific method redirects the enquirer to the social aspects of scientific inquiry. One significant achievement of kuhn's project is the demystification of notion of objectivism. Thus, beyond the confines of the traditional understanding of knowledge as either objective or relative, we realize that these two concepts do not exhaust all there is and can be in epistemic inquiry and that truth and rational certainty go beyond the ideas of objectivism and relativism.

Apparently, the notion of objectivity is no longer as popular as it used to be among contemporary philosophers of science and epistemologists. This does not imply that relativism, which is the other more to towards the lines of the social dimensions and implications of inquiry. While I acknowledge the multifarious enterprises that come under the current discourse on SE, which has surged since the year 2000, I have no doubts that it characterizes the evolution of knowledge. From the Platonic-Cartesian focus on the individual cognitive agent's doxastic states on which TE flourished; seeking objective knowledge, epistemic inquiry has evolved to include within its catchment the implication of social relations for knowledge practice. Focus in contemporary epistemic discussions is now on the social dimensions of cognition. Although W.V.O Quine's "naturalized epistemology" foreshadows this evolution, it took a definite turn with Kuhn's deconstruction of science, which sufficiently shows that objectivity as universal standards and paradigms for epistemic inquiry into truth and rational certainty is a misconception.

\section{References}

1. D' Abro A (1927) The evolution of scientific thought: From Newton to Einsten. Newyork: Boni and Liveright.

2. Goldman A (2011) "A guide to social epistemology". In: Alvin IG, Dennis W (Eds.), Social epistemology: essential readings.

3. Jimoh AK (2013) Certitude and doubt: a study guide in epistemology. Ibadan: Ebony Books and Kreations.

4. Wray BK (2011) Kuhn's evolutionary social epistemology. Cambridge: Cambridge University press.

5. Swoyer C (2014) Relativism. In: Edward NZ (ED), The Stanford Eenclyclopedia of Philosophy.

6. David P (1996) The problems of the history of Science. In: Bunnin N, Tsui-James EP (Eds.), The Blackwell companion to Philosophy. London: Blackwell.

7. Mulder DH (2019) "Objectivity". Internet Enclyclopedia of Philosophy.

8. Westacott E (2019) "Relativism". Internet Encyclopedia of Philosophy.

9. Luper S (2019) "Epistemic relativism". Philosophical issues 14(1): 271-295.

10. Schmitt F (1994) "Socializing epistemology: an introduction through two sample issues". In: Schmitt FF (Ed.), Socializing epistemology: The social dimensions of Knowledge, Lanham: Rowman and Littlefield.

11. Freeman Dyson, The Sun, the genomes and the internet: tools of Scientific revolutions, (Oxford: Oxford University Press,1999) 
12. Ozumba GO (2001) The philosophy of logical positivism and the growth of science. Ccalabar: Bacos.

13. Reiss J, Sprenger J (2014) "Scientific Objectivity". In: Zalta EN (Ed.), The Stanford Encyclopedia of Philosophy.

14. Williams M (2007) Why Wittgensteinian contextualism is not relativism. Episteme: A Journal of social Epistemology 4(1): 93-114.

15. Baghramian M, Carter A (2015) "Relativism". The Stanford Encyclopedia of Philosophy.

16. Paul K Mosser (1993) Philosophy and after Objectivity: making sense in perspective. Oxford: Oxford University Press.

17. Russel L Ackoff (1962) Scientific method: optimizing applied research decisions. NY: John wiley and Sons.
18. Okasha S (2002) Philosophy of Science: a very short introduction. NY: Oxford University Press.

19. Fuller S (1999) The governance of Science: ideology and the future of the open society. Buckingham: Open University Press.

20. Kuhn TS (1961) "The function of dogma in scientific research". In: Crombie AC (Ed.), Scientifichange, Synposium on the History of Science, Oxford University, NY and London: Basic Books and Heinemann.

21. Kuhn TS (1970) The structure of scientific revolutions. $2^{\text {nd }}$ (Edn.), Chicago: University of Chicago press.

22. Schmaus Warren (2008) "A new way of thinking about social location in science". Science and Education.

23. Sharrock W, Read R (2002) Kuhn: Philosopher of scientific revolutions. U.S.A: Polity. 